\title{
A Case of Radiation Induced Osteosarcoma of Proximal Humerus in Undifferentiated Nasopharyngeal Carcinoma
}

Lamiae Amaadour*, Hajar Ouahbi, Zineb Benbrahim, Fatimazahra Elmrabet, Samia Arifi and Nawfel Mellas

Department of Medical Oncology, Hassan II University Hospital of Fez, Morocco

\section{Abstract}

Radiation-induced osteosarcomas (RIOS) after nasopharyngeal carcinomas are rare complication of radiotherapy and are associated with poor prognosis. Few cases are reported in the literature.

Case report: We report a case of radiation-induced osteosarcoma involving the proximal humerus in a patient treated with radiotherapy for nasopharyngeal carcinoma (NPC) nine years ago. Surgical treatment could not be performed, and the patient received induction chemotherapy. He died from disease spread after three cycles

Conclusion: RIOS after treatment of NPC is very aggressive complication. Only a regular follow up of treated patient allow early detection of these tumors and best chances of survival.

Keywords: Radiation therapy; Osteosarcoma; Nasopharyngeal carcinoma; Prognosis

\section{Background}

Radiation-induced osteosarcomas (RIOS) are rare complication of radiotherapy and are associated with poor prognosis. They represent $5.5 \%$ of all osteosarcomas [1]. RIOS occur mostly after treatment of breast cancer, lymphoma, pelvic cancer, or Ewing sarcoma [2,3]. Nasopharyngeal carcinoma is the most frequent tumor of head and neck in North Africa and high doses of radiotherapy in localized stages is the mainstay of treatment. Reports of RIOS in patients who were treated for nasopharyngeal carcinoma are limited. We report here in a rare case of RIOS of proximal humerus having occurred nine years after treatment of nasopharyngeal carcinoma, and we review the existing literature data of RIOS after treatment of nasopharyngeal carcinomas [4].

\section{Case Report}

A 25 year-old man was treated in 2007 for stage III (T2bN2M0) undifferentiated nasopharyngeal carcinoma. He had received three courses of induction chemotherapy based on Bleomycin-EtoposidCisplatin regimen followed by radiotherapy. The radiation dose was 70 gray, in 35 fractions, five days per week, delivered using the classic 3 field's technique (2 lateral opposed fields abutted to an anterior lowneck field). He presented nine years later to emergency department for pathologic fracture of his left shoulder. Radiograph showed medullary and cortical bone destruction of proximal humerus with an underlying pathologic fracture (Figure 1). CT scan showed a locally advanced lytic neoplasic lesion of proximal humerus (Figure 2). Ct scan of chest and abdomen revealed no distant metastases. Histological examination of the bony mass showed proliferation of spindle shaped cells with atypical mitosis and associated with osteoid matrix. Immunohistochemistry showed expression of vimentin and S100 protein. These findings were consistent with osteosarcoma. As the tumor was unrespectable, neoadjuvant chemotherapy was then started with doxorubicin $60 \mathrm{mg} /$ $\mathrm{m}^{2}$ (days 1 and 15), cisplatin $100 \mathrm{mg} / \mathrm{m}^{2}$ (day 1), and Ifosfamide $5 \mathrm{~g} / \mathrm{m}^{2}$ (days 2 and 15), with an equivalent dose of mesna and growth factor support. The tumor showed clinical and radiological progression after three cycles of chemotherapy and the patient died one month later (Figures 1 and 2).

\section{Discussion}

Radiation-induced sarcomas are rare but a well-known late complication of radiotherapy. The incidence of RIOS is rising due to increased survival as a results of improved treatments of nasopharyngeal carcinoma (NPC) [5,6]. RIOS account for $0.01-0.03 \%$ of all irradiated patients [1,7], and $0.03-0.8 \%$ of all NPC patients $[5,8]$. The most frequent radiation-induced tumors are fibrosarcoma and osteosarcoma. The maxilla and the mandible are the most common RIOS sites in NPC followed by nasal cavity and para-nasal sinuses [5]. To the best of our knowledge, our case is the first to describe proximal humerus as a site of RIOS in NPC. The diagnosis of RIOS is based on four criteria established by Cahan et al in 1984 that are still valid today: the origin of the neoplasm in the radiation field, the nonmalignant nature of the initial bone condition, the histological diagnosis of the

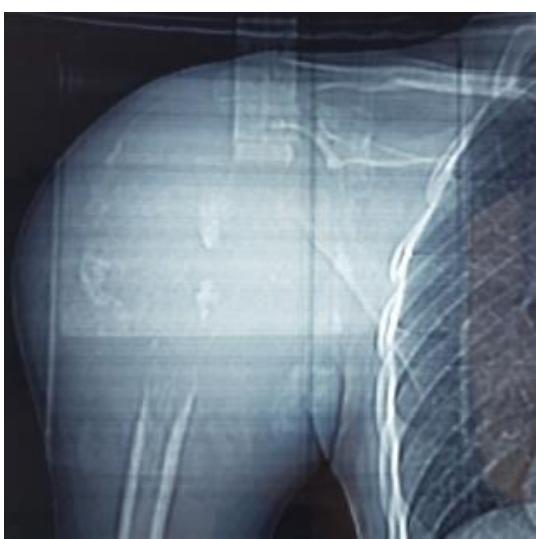

Figure 1: Radiograph showing pathologic fracture of proximal humerus.

*Corresponding author: Amaadour L, Department of Medical Oncology, Hassan II University Hospital, Fez, Morocco, Tel: +212 5356-19053; E-mail: lamiae.amaadour@gmail.com

Received November 10, 2017; Accepted November 30, 2017; Published December 03, 2017

Citation: Amaadour L, Ouahbi H, Benbrahim Z, Elmrabet F, Arifi S, et al. (2017) A Case of Radiation Induced Osteosarcoma of Proximal Humerus in Undifferentiated Nasopharyngeal Carcinoma. J Cytol Histol 8: 490. doi: 10.4172/2157-7099.1000490

Copyright: (c) 2017 Amaadour L, et al. This is an open-access article distributed under the terms of the Creative Commons Attribution License, which permits unrestricted use, distribution, and reproduction in any medium, provided the original author and source are credited. 


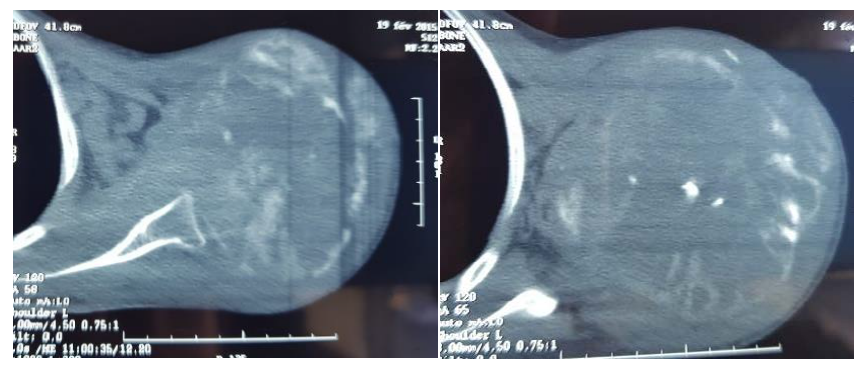

Figure 2: CT scan images of locally advanced osteosarcoma of proximal humerus.

neoplasm, and a relatively long latency period [9]. Our patient fulfilled all these criteria. The latent period following radiation therapy for nasopharyngeal carcinoma and the development of secondary tumors is 5-30 years with a mean of 12.9 years [5,10]. Some researchers have suggested that the minimum radiation dose needed for development of radiation-induced sarcoma is $30 \mathrm{~Gy}[11,12]$. The radiation doses in reported cases varied from 25 to $110 \mathrm{~Gy}$, with a median dose of $45 \mathrm{~Gy}$ [13]. Our patient received 70 Gy which is much higher than the median dose previously mentioned. The pathogenesis of RIOS is unknown. It is suggested that the patients who have genetic predisposition like Li-Fraumeni syndrome, von Recklinghausen's disease, mutations in tumor suppressor genes including $\mathrm{p} 53$ and $\mathrm{RB} 1$, are more prone to develop RIOS $[14,15]$. The patient age at radiation exposure and association of chemotherapy have also been identified as risk factors for RIOS [16]. The CT scan shows bone destruction, soft tissue mass and osteoneogenesis while the MRI is good in defining the extension into the adjacent soft tissues in osteosarcomas. In our case, the MRI was not performed before treatment because of financial considerations, but it was programmed after the first three cycles to evaluate respectability.

The treatment of high grade osteosarcomas, irrespective of etiology includes radical surgery with perioperative chemotherapy. Although formal proof that giving chemotherapy preoperatively improves the outcome per se is lacking, disease free survival probabilities increases with multimodal treatment from $10-20 \%$ to up to $60 \%$ compared with surgery alone [17]. The goal of surgery is to remove the tumor with adequate surgical margins and yet preserve as much function as possible. Obtaining negative margins is crucial to local control as well as recurrence-free survival [18].

The prognosis of radiation-induced sarcoma is generally thought to be worse than primary sarcomas, regardless of site. The cumulative disease-free survival at 5 years for patients with a RIOS was $17 \%$, with a median survival estimate of 1 year [14]. In order to prevent radiationinduced tumors, it is important to be meticulous in radiation doses in planned fields. In our case, the preferred radiation dose is lower now than in the past for the treatment of nasopharyngeal carcinoma. Moreover, the exposure of normal tissue to radiation is decreased by intensity modulation radiotherapy and the addition of chemotherapy [13].

\section{Conclusion}

Radiation-induced osteosarcoma of proximal humerus after treatment of nasopharyngeal carcinoma is exceptional but very aggressive complication with poor prognosis as highlighted in this case. Regular follow up of treated patients should be considered.

\section{Conflicts of Interest}

All the authors declare no conflict of interest.

\section{References}

1. Salvati M, Ciappetta P, Raco A (1993) Osteosarcomas of the skull: clinical remarks on 19 cases. Cancer 71: 2210-2216.

2. Beaty O 3rd, Hudson MM, Greenwald C (1995) Subsequent malignancies in children and adolescence after treatment for Hodgkin's disease. J Clin Oncol 13: 603-609.

3. Amichetti M, Boi S (1993) Postirradiation sarcoma in a patient treated for testicular seminoma. Oncology 50: 264-266.

4. Lee AW, Sze WM, Au JS, Leung SF, Leung TW, et al. (2005) Treatment for nasopharyngeal carcinoma in the modern era: the Hong Kong experience. Int $J$ Radiat Oncol Biol Phys 61: 1107-1116.

5. Liu WW, Wu QL, Wu GH, Chen ZH, Zeng ZY (2005) features, treatment, and prognosis of postirradiation osteosarcoma in patients with nasopharyngeal cancer. Laryngoscope 115: 1574-1579.

6. Zhang LF, Li YH, Xie SH, Ling W, Chen SH, et al. (2015) Incidence trend of nasopharyngeal carcinoma from 1987 to 2011 in Sihui County, Guangdong Province, South China: an age-period-cohort analysis. Chin J Cancer 34: 350357.

7. Goodman MA, McMaster JH (1976) Primary osteosarcoma of the skull. Clin Orthop Relat Res 120: 110-114.

8. Mark RJ, Poen J, Tran LM, Fu YS, Selch MT, et al. (1994) Postirradiation sarcomas. A single-institution study and review of the literature. Cancer 73: 2653-2662.

9. Cahan WG, Woodard HQ, Higinbotham NL, Stewart FW, Coley BL (1998) Sarcoma arising in irradiated bone: report of eleven cases. Cancer 82: 8-34.

10. Abrigo JM, King AD, Leung SF, Vlantis AC, Wong JKT, et al. (2009) MRI of radiation-induced tumors of the head and neck in post-radiation nasopharyngeal carcinoma. Eur Radiol 19: 1197-1205.

11. Scélo G, Boffetta P, Corbex M, Chia KS, Hemminki K, et al. (2007) Second primary cancers in patients with nasopharyngeal carcinoma: a pooled analysis of 13 cancer registries. Cancer Causes Control 18: 269-278.

12. Makimoto $\mathrm{Y}$, Yamamoto $\mathrm{S}$, Takano $\mathrm{H}$, Motoori $\mathrm{K}$, Ueda T, et al. (2007) Imaging findings of radiation-induced sarcoma of the head and neck. $\mathrm{Br} \mathrm{J}$ Radiol 80: 790-797.

13. Patel SR (2000) Radiation-induced sarcoma. Curr Treat Options Oncol 1: 258-261.

14. Penel N, Nisse C, Feddal S, Lartigau E (2001) Epidémiologie des sarcomes des tissus mous de l'adulte," La Presse Médicale 30: 1405-1413.

15. Friend SH, Bernards R, Ragelj S (1986) A Human DNA segment with properties of the gene that predisposes to retinoblastoma and osteosarcoma. Nature 323 643-646.

16. Leclercq C, Penel N, Grosjean J, Fournier C, Vilain MO, et al. (2004) Prognosis of post-irradiation soft-tissue sarcoma: case-control study. La Revue de Médecine Interne 25: 866-871.

17. Bone sarcomas (2014) ESMO Clinical Practice Guidelines for diagnosis, treatment and follow-up. Annals of Oncology 25: 113-123.

18. Picci P, Sangiorgi L, Rougraff BT (1994) Relationship of chemotherapyinduced necrosis and surgical margins to local recurrence in osteosarcoma. $J$ Clin Oncol 12: 2699-2705. 